\title{
Outdoor Walking Speeds of Apparently Healthy Adults: A Systematic Review and Meta-analysis
}

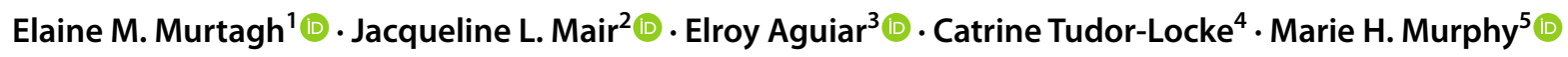

Published online: 8 October 2020

(c) The Author(s) 2020

\begin{abstract}
Background Walking outdoors can be used by many individuals to meet public health guidelines for moderate-to-vigorousintensity physical activity. The speed at which adults walk may be a proxy for intensity. Traditional estimates of indoor walking speed are unlikely to reflect self-selected usual or other instructed paces of outdoor walking speed.

Objective To inform estimates of pace-based walking speed of apparently healthy adults in outdoor settings.

Methods We searched four electronic databases for articles published in English between January 1970 and March 2019. Studies that reported walking speed $(\mathrm{m} / \mathrm{s})$, cadence (steps $/ \mathrm{min})$, or intensity $(\mathrm{mL} / \mathrm{kg} / \mathrm{min})$ of ambulatory, apparently healthy, and community-dwelling adults ( $>18$ years) were included. Walking speed categories were defined according to the description provided in each study. Meta-analysis was used to synthesise speed, cadence, and intensity data by slow, usual, medium, fast, and maximal pace (where reported).

Results Thirty-five studies, representing 14,015 participants (6808 women, 5135 men, and 2072 sex not specified), were identified. The mean $(95 \%$ CI) walking speed for slow, usual, medium, fast, and maximal pace was $0.82(0.77-0.86), 1.31$ (1.27-1.35), 1.47 (1.44-1.49), 1.72 (1.64-1.81), and $1.62(1.45-1.79) \mathrm{m} / \mathrm{s}$, respectively. Mean cadence (95\% CI) for usual and fast paces were 116.65 (114.95-118.35) and 126.75 (121.87-131.63) steps/min, respectively. The mean oxygen consumption $(95 \% \mathrm{CI})$ for the usual and medium paces was $11.97(11.69-12.25)$ and 13.34 (12.94-13.73) $\mathrm{mL} / \mathrm{kg} / \mathrm{min}$, respectively. Conclusion These findings provide greater clarity with regard to how various indicators of enacted walking pace, speed, and intensity overlap and how each can be best communicated in the real-world setting to optimise health-related outcomes. Pace-based instructions can be used to support walking in outdoor settings within public health guidelines.
\end{abstract}

Electronic supplementary material The online version of this article (https://doi.org/10.1007/s40279-020-01351-3) contains supplementary material, which is available to authorized users.

Elroy Aguiar

ejaguiar@ua.edu

Elaine M. Murtagh

elaine.murtagh@ul.ie

Jacqueline L. Mair

jacqueline.mair@uws.ac.uk

Catrine Tudor-Locke

Tudor-Locke@uncc.edu

Marie H. Murphy

mh.murphy@ulster.ac.uk

1 University of Limerick, Limerick, Ireland

2 University of the West of Scotland, Glasgow, UK

3 University of Alabama, Tuscaloosa, USA

4 University of North Carolina at Charlotte, Charlotte, USA

5 Ulster University, Newtownabbey, UK

\section{Key Points}

We reviewed studies that measured walking speed of apparently healthy adults in outdoor settings.

We provide expected values for speed, cadence, percent maximal heart rate, and oxygen consumption for slow through maximal paced walking.

Walking outdoors at a usual pace was associated with an average speed of $1.31 \mathrm{~m} / \mathrm{s}$, a cadence of 116.65 steps/ $\mathrm{min}$, and an oxygen consumption of $11.97 \mathrm{~mL} / \mathrm{kg} / \mathrm{min}$, meeting/exceeding public health thresholds. 


\section{Introduction}

Walking is the most commonly reported exercise among adults [1]. Walking demands little skill, facility, or equipment requirements and is socially acceptable for most individuals across most cultures worldwide making it the near-perfect form of exercise [2]. Outside of purposeful exercise, walking is also commonly performed in the course of daily personal transport/commuting, recreation, or domestic/occupational activities. Given the dose-response relationship between physical activity and health and the disproportionate population health gains derived from encouraging the most inactive to increase activity [3], walking has become the cornerstone of physical activity promotion for public health and the gateway through which inactive and low active individuals can initiate access to these benefits.

Current physical activity guidelines recommend that adults accumulate at least $150 \mathrm{~min}$ of moderate-intensity physical activity each week [4]. As implied, the health benefits of walking depend, in part, on its intensity [5]. Although walking volume metrics (time, distance, and/ or accumulated steps) have become common parlance in health promotion, there is less clarity regarding accessible expressions of intensity (traditionally expressed in physiological terms as rate of oxygen consumed or $\mathrm{mL} / \mathrm{kg} / \mathrm{min}$ relative to an individual's maximum). Alternatively, walking speed may be a proxy for intensity. Irrespective of level of personal fitness, walking at a faster speed results in a higher relative exercise intensity and, therefore, presents a greater stimulus for health benefit. It has been repeatedly demonstrated that walking speed is a stronger predictor of risk than volume in terms of all-cause mortality, heart failure, and disease risk, across a continuum of volumes $[6,7]$. Speed-based intensity recommendations have been derived primarily from laboratory studies; the only published meta-analysis of walking speed did not distinguish between indoor and outdoor settings [8]. Walking speed thresholds determined in clinical settings have been used to classify walking independence [9], as part of geriatric assessment [10], and as a summary indicator of frailty [11]. Limitations of assessing walking speed in the clinical setting include measurement noise, bias due to brevity, and variability due to participants' motivation and learning effect [12]. Thus, controlled walking in the laboratory setting is not representative of pace-based speeds enacted during the course of daily living. Determining the speed individuals choose to walk in different contexts or in response to specific instructions, and the physiological demands of these self-selected paces, may help those promoting walking to ensure that advice on walking pace is likely to result in moderate to vigorous physical activity and, therefore, contribute to meeting current PA guidelines. The primary objective of this systematic review and meta-analysis was to inform estimates of pace-based walking speed of apparently healthy adults in outdoor settings.

\section{Methods}

The protocol for this systematic review and meta-analysis was registered with PROSPERO: International prospective register of systematic reviews (registration number CRD42017051911) [13].

\subsection{Inclusion Criteria}

We included observational, randomised-controlled trials and pre-post intervention studies involving ambulatory, apparently healthy (free-living adults without a clinical diagnosis of disease), community-dwelling adults ( $>18$ years of age). All walking assessments were conducted outdoors (i.e., not on a treadmill or in any other controlled indoor space). Studies were excluded if they focused exclusively on adults with lower limb conditions, musculoskeletal conditions, or gait issues that may have impaired walking ability, in-hospital patients, or clinical populations. If a study included an experimental group involving a clinical population and a "healthy" control group, the study was incorporated to allow inclusion of data collected from the control group.

The primary outcome of interest was pace-based outdoor walking speed, either freely chosen or in response to a verbal instruction, measured over a distance of at least $3 \mathrm{~m} \mathrm{(10}$ feet). Studies were included if they reported speed in quantitative units (e.g., $\mathrm{m} / \mathrm{s}, \mathrm{km} / \mathrm{h}$ ). Studies were excluded if the walking protocol involved an abrupt change of direction. Secondary outcomes included any other direct or indirect indicator of intensity (e.g., cadence, metabolic equivalents (METs), percent maximal heart rate $\left(\mathrm{HR}_{\max }\right)$, percent maximal aerobic capacity, and energy expenditure).

\subsection{Search and Selection}

We searched the following electronic databases for English language articles published between January 1970 and March 2019: OVID (Medline), CINAHL, SCOPUS, and Web of Science. We hand-searched reference lists of identified studies and systematic reviews to identify potentially relevant studies. The full electronic search strategy is presented in Electronic Supplementary Material Appendix S1.

We used online software Covidence to manage the study selection process [14]. Two authors (JM and EA) independently screened titles and abstracts to exclude records that did not meet the inclusion criteria for the review. A third author (EM) adjudicated any disagreements. The full-text 
versions of potentially eligible studies were then reviewed independently by at least two of the team of three authors (JM, EA, and EM). Disagreements were resolved through consensus. We collated multiple reports of the same study and treated one unique parent study as the unit of interest.

\subsection{Data Extraction}

Data were extracted by one author (JM) using a pre-piloted data extraction form prepared using Microsoft Excel. A second author (EM) checked $20 \%$ of data for accuracy [15]. Disagreements were resolved by consensus. Extracted data included: (1) study setting (country, test location/surface); (2) participant characteristics (sex, age, height, body mass, and body mass index [BMI]); (3) method of measuring walking speed (test protocol); (4) walking pace category (description of pace provided in the original text); (5) walking speed (in originally reported units); (6) cadence, and (7) intensity (where and as reported). Study authors were contacted when specific data were missing or unclear [16-19]. The online software WebPlotDigitizer version 4.1 (https://automeris.io/ WebPlotDigitizer) was used to extract data from a figure in one study [20].

\subsection{Quality Assessment}

The NIH tool for Assessing the Quality of Observational Cohort and Cross-Sectional Studies was adapted to examine whether there was potential for bias in each study [21]. The following six questions were deemed directly relevant to our study purpose:

1. Was the research question or objective in this paper clearly stated?

2. Was the study population clearly specified and defined?

3. Was the participation rate of eligible persons at least $50 \%$ ?

4. Were all the subjects selected or recruited from the same or similar populations (including the same time period)? Were inclusion and exclusion criteria for being in the study pre-specified and applied uniformly to all participants?

5. Was a sample size justification, power description, or variance and effect estimates provided?

6. Were the outcome measures (dependent variables) clearly defined, valid, reliable, and implemented consistently across all study participants?

Assessments were made independently by two authors (MM, CTL), with any disagreements resolved by a third author (EM). Assessors could select 'yes', 'no', or 'other (cannot determine, not applicable, and not reported)' for each question.

\subsection{Analysis and Synthesis}

Walking speed was converted to $\mathrm{m} / \mathrm{s}$ where necessary. For studies with several measurements of walking speed conducted at different time points (e.g., in the case of prospective studies), each measure was treated as a separate data point. The summary measures for all outcomes were mean and its associated standard deviation. Walking speed outcomes were categorised according to the description of walking pace provided in each study or the instruction given to participants (e.g., fast- "walk briskly" or "walk as fast as possible"). We collapsed synonymous pace terms into single categories based on the descriptions of pace that were provided in the original text; e.g., if a study described the pace as habitual/usual/normal/self-paced, it was assigned to the "usual category". To avoid confusion between similar modifying terminology related to pace and intensity, we decided to reserve the adjective "medium" to describe pace (even if the original article described an instruction to "walk at a pace corresponding with moderate intensity") and the adjective "moderate" to specifically describe intensity throughout.

Meta-analyses were conducted for each outcome of interest (walking speed, cadence, METs, percentage $\mathrm{HR}_{\max }$, oxygen consumption, and energy expenditure). A minimum of three studies was deemed necessary to perform meta-analyses for each pace instruction/description category. The random-effects model was used as it allows for a greater level of natural heterogeneity between studies. Pooled results were reported as weighted mean with $95 \%$ confidence intervals. The $\mathrm{I}^{2}$ statistic was used to quantify the level of heterogeneity present. Pre-specified sub-group analysis of outcomes by sex was conducted where relevant data were available.

\section{Results}

Following removal of duplicates, a total of 9594 articles were identified by electronic searches and 11 additional articles from hand-searching strategies. After screening the title and abstract of the 9605 articles identified, 8049 were excluded as they did not meet inclusion criteria. The full-text versions of 1556 articles were then reviewed. Authors of 42 studies were contacted to confirm whether or not the measure of walking speed was conducted in an outdoor setting. Multiple reports of the same study were collated [22, 23]. Ultimately, 36 articles, representing 35 unique studies, were deemed eligible for inclusion. The reasons for exclusion at various stages of the search process are presented in Fig. 1.

The characteristics of identified studies are summarised in Table 1. All studies were observational in design. No randomised-controlled trials or pre-post intervention studies met the inclusion criteria. Studies were conducted in 


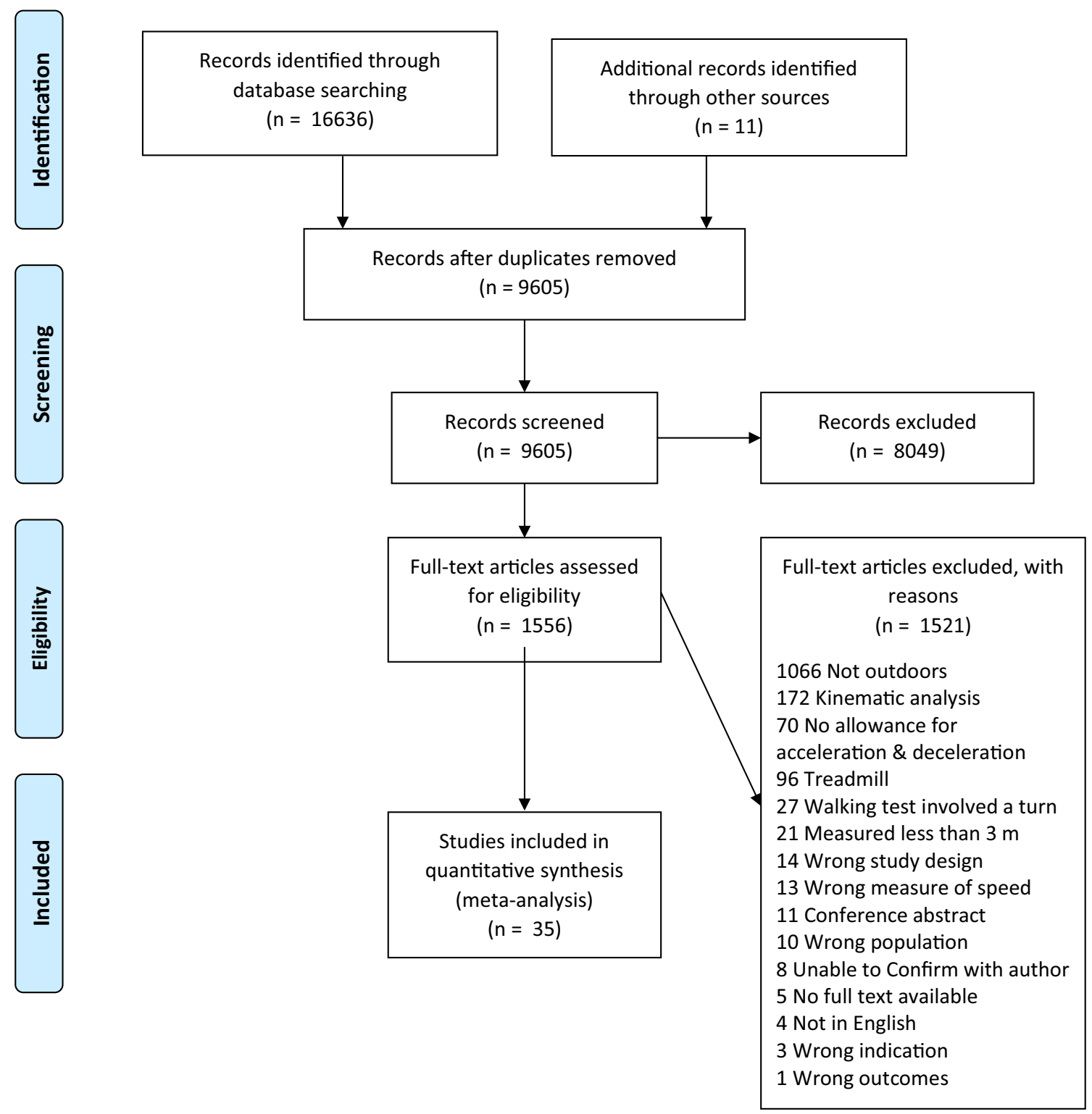

Fig. 1 PRISMA flow diagram

13 countries, with the majority of studies conducted in Australia $(n=8)$, followed by USA $(n=7)$, and France and the UK (4 studies each). The identified studies represented 14,015 participants (6808 women, 5135 men, 2072 sex not specified), ranging in age from 18 to 90 years (mean $=44 \pm 17$ years). Mean BMI calculated from available data presented in 15 studies was $24.8 \pm 3 \mathrm{~kg} / \mathrm{m}^{2}$. The setting for measurement of outdoor walking speed varied across studies. The most frequently reported location was a path/track (20 studies). Other settings included: pavement/sidewalk (5 studies), athletics track (3 studies), grass (1 study), road intersection/crossing (2 studies), mixed terrain (2 studies), and unspecified outdoor settings (2 studies).
Potential for risk of bias, assessed using the NIH tool for Assessing the Quality of Observational Cohort and CrossSectional Studies, is shown in Table 2. No study demonstrated low risk of bias across all domains.

Results of the meta-analyses for walking speed according to pace instruction/description category are shown in Table 3. The mean walking speed for slow, usual, medium, fast, and maximal was $0.82 \pm 0.02 \mathrm{~m} / \mathrm{s}$ ( 9 study groupings, $n=201), 1.31 \pm 0.02 \mathrm{~m} / \mathrm{s}$ (111 study groups, $n=13,609$ ), $1.47 \pm 0.01 \mathrm{~m} / \mathrm{s}$ ( 5 study groups, $n=208), 1.72 \pm 0.05(19$ study groups, $n=916$ ), and $1.62 \pm 0.09 \mathrm{~m} / \mathrm{s}$ (7 study groups, $n=2172$ ) respectively (Fig. 2 ). The only sex-specific comparison that could be performed demonstrated that men walked faster than women in response to instruction to walk 


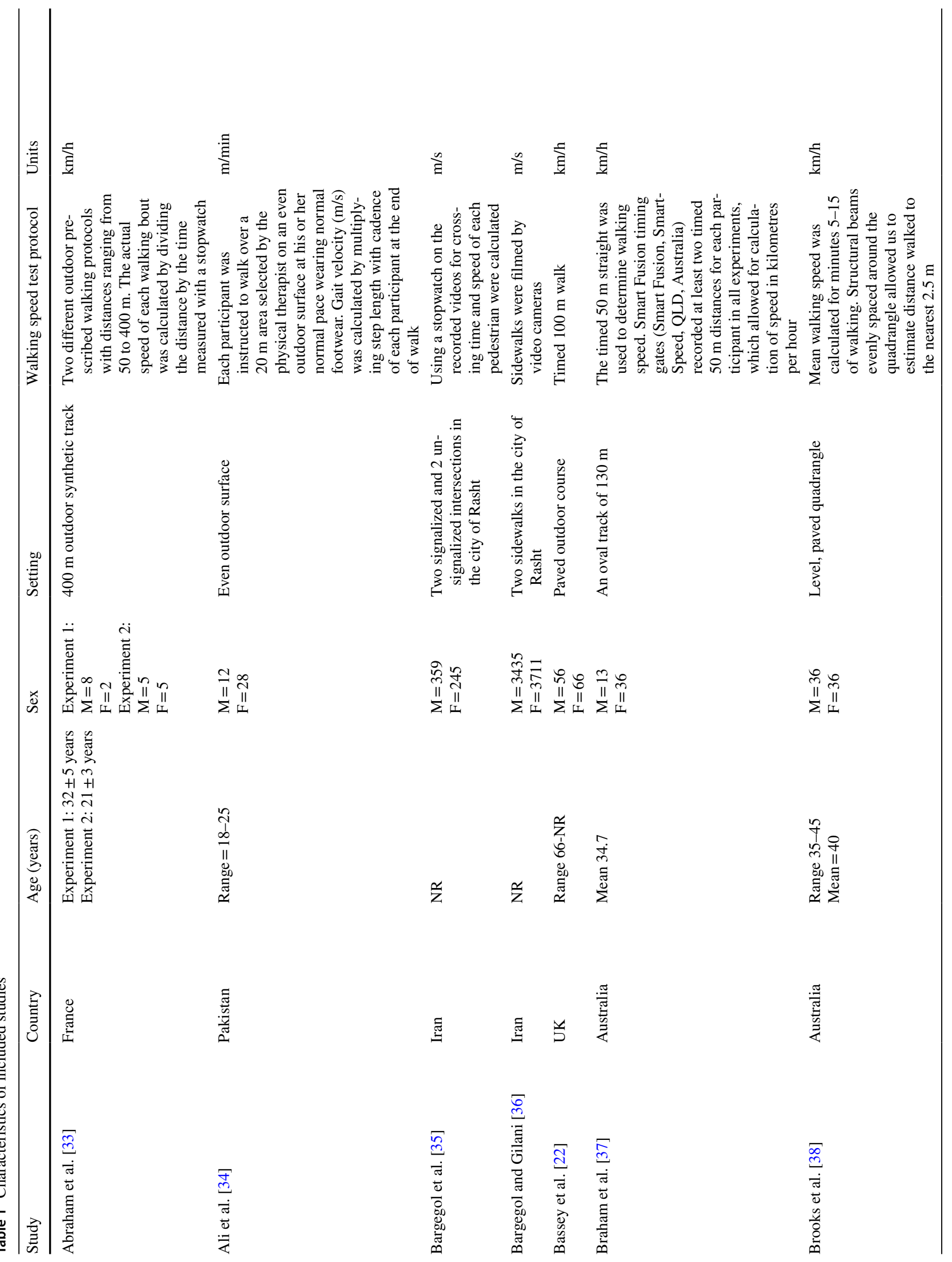




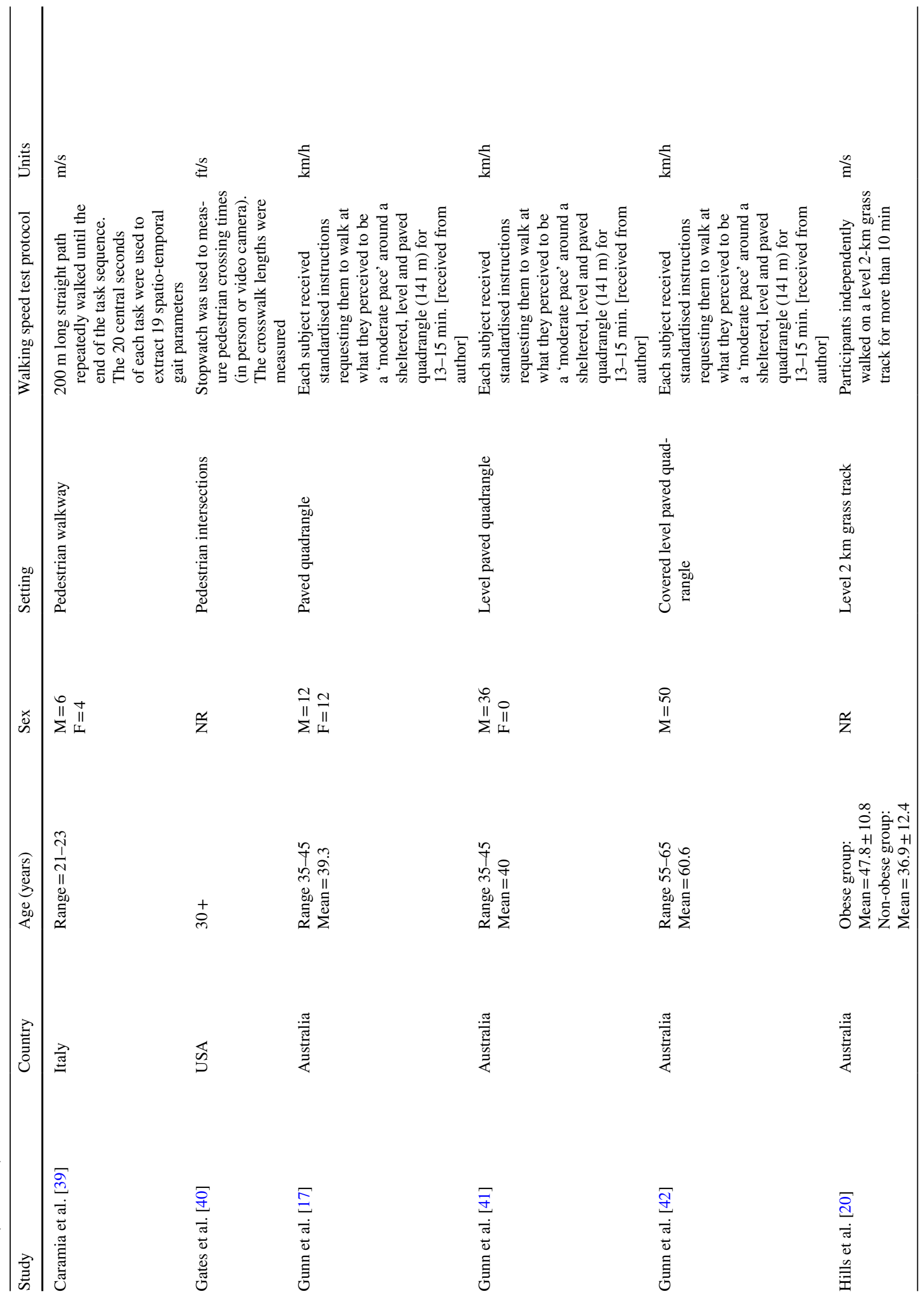




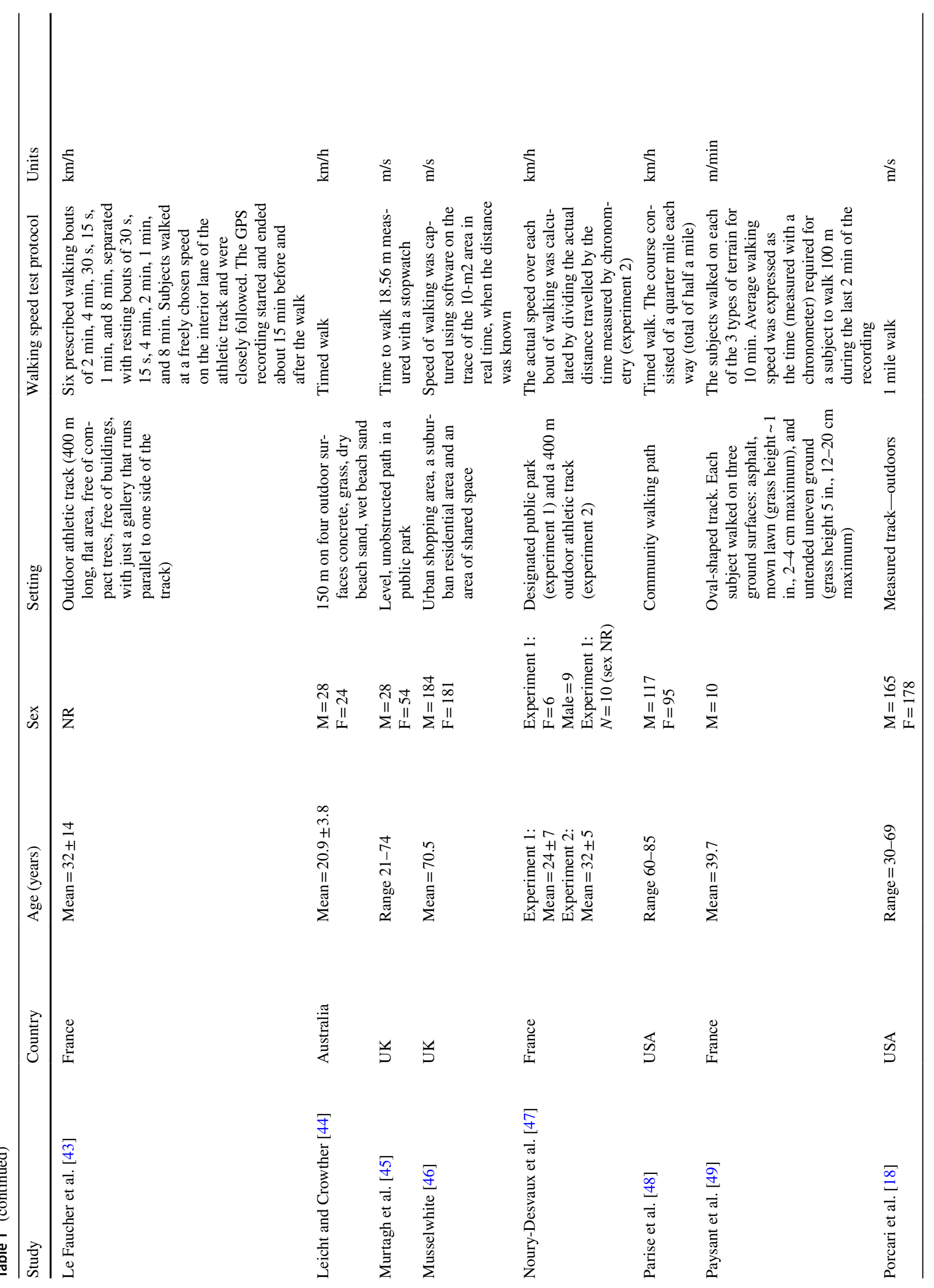




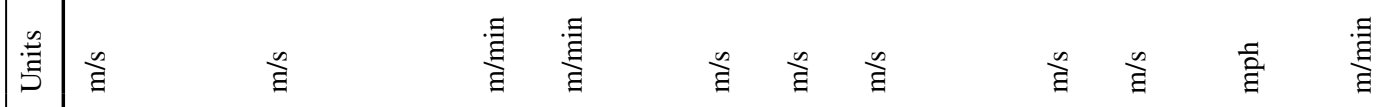

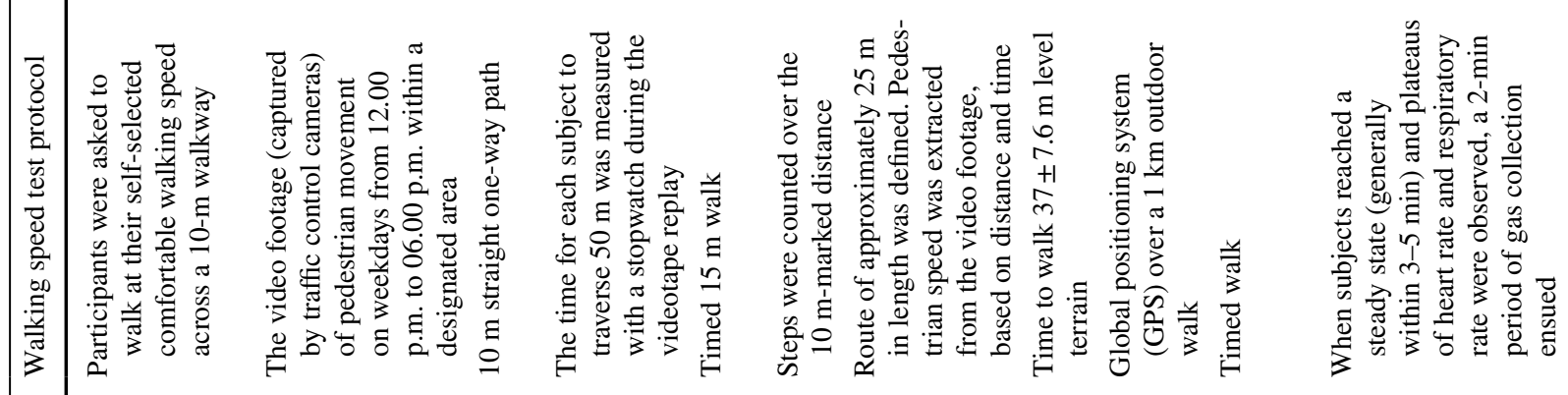

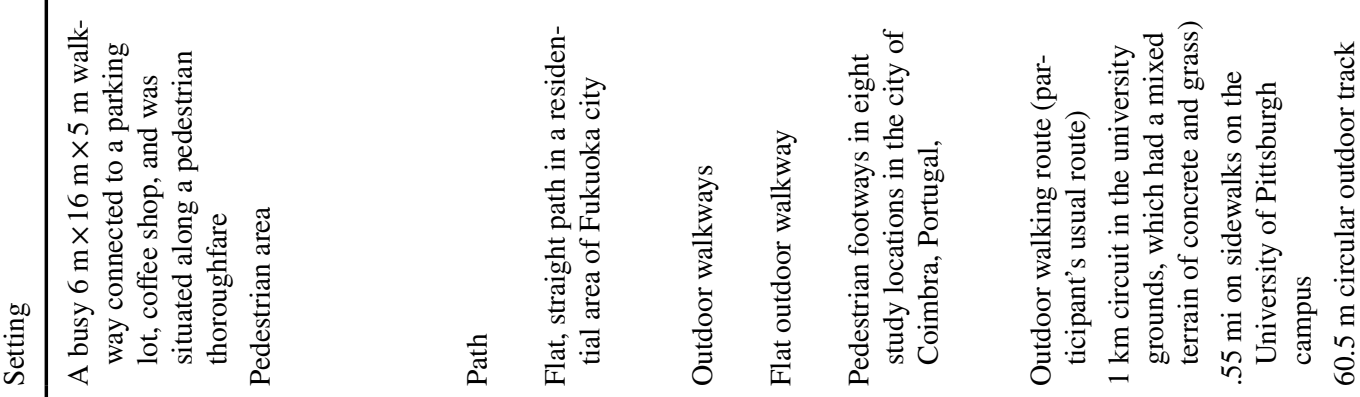

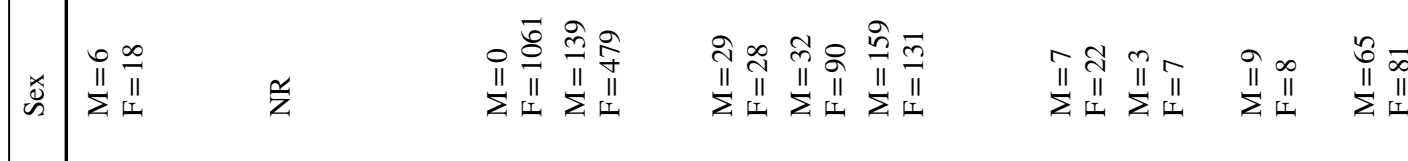

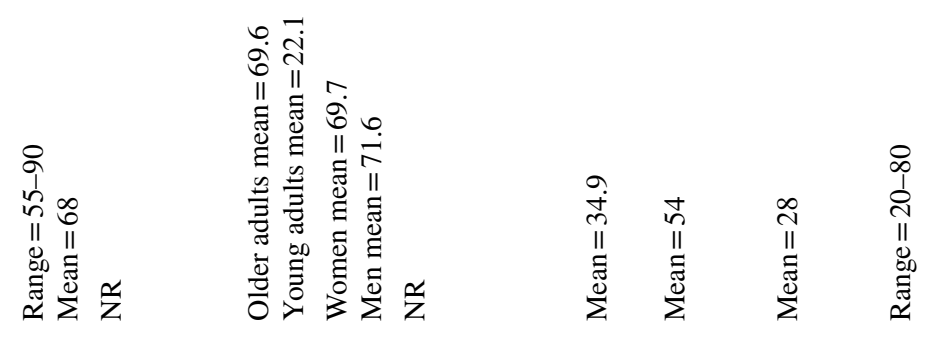

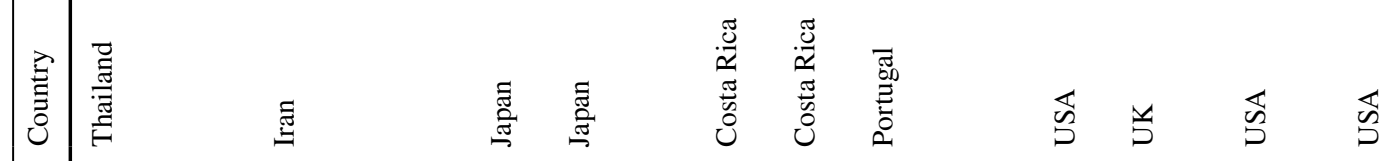

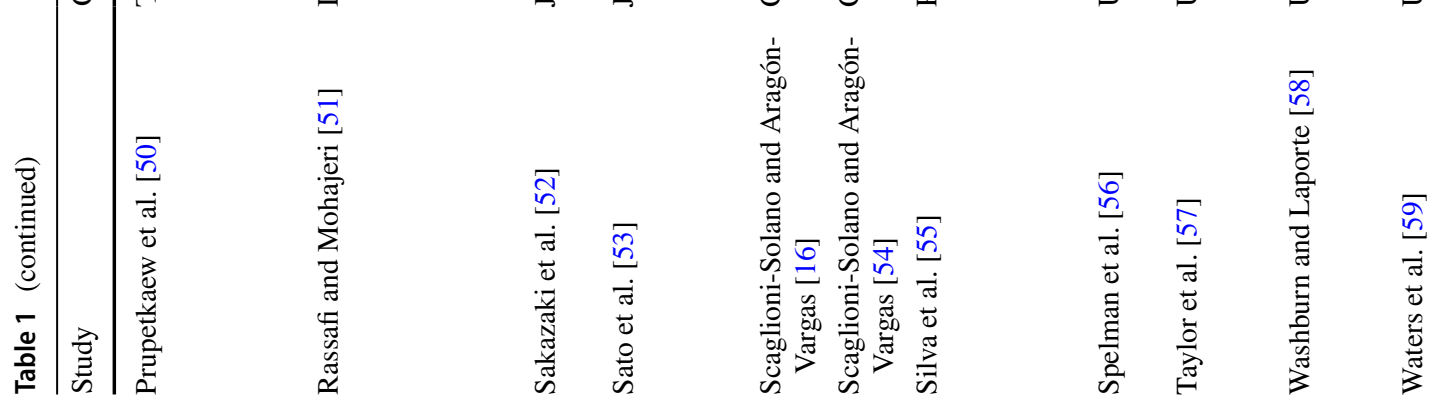




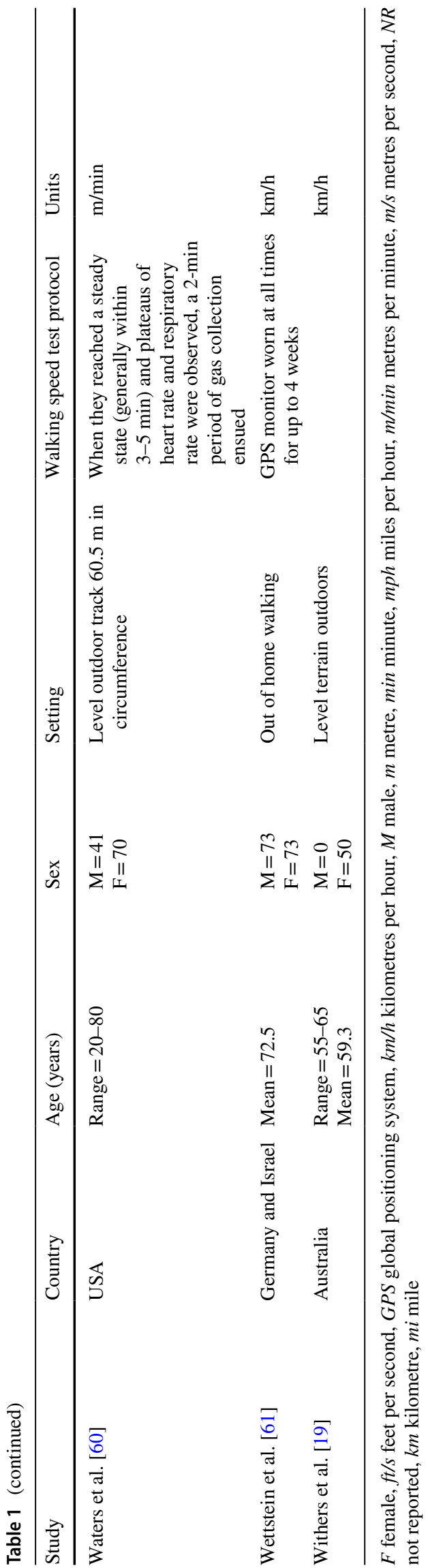

at a usual pace $(P=0.03)$. Results of the meta-analysis for walking cadence according to pace instruction are presented in Table 4. Mean cadence for usual and fast paces were $116.65 \pm 0.87$ (45 study groups, $n=939$ ) and $126.75 \pm 2.49$ steps/min (6 study groups, $n=268$ ), respectively (Fig. 3). There was a significant difference by sex $(P<0.01)$ for usual walking pace, with women performing higher steps/min than men (121.88 vs 121.88$)$ at this pace.

In terms of absolute intensity, participants walked at $4.21 \pm 0.14$ METs (medium pace, 7 study groupings, $n=232$ ). Relative intensity for a medium pace was $55.86 \pm 0.89 \% \mathrm{HR}_{\max }$, (4 study groups, $n=158$ ). There was a significant difference between women and men, with women exhibiting a higher percentage $\mathrm{HR}_{\max }$ than men $(61.0 \mathrm{vs}$ $53.1 \% \mathrm{HR}_{\text {max }}$; see Table 5).

Table 6 shows findings for meta-analyses of oxygen consumption and energy expenditure outcomes according to pace instruction. The mean oxygen consumption for the usual and medium pace instructions was $11.97 \pm 0.14 \mathrm{~mL} /$ $\mathrm{kg} / \mathrm{min}$ (11 study groups, $n=287$ ) and $13.34 \pm 0.20 \mathrm{~mL} / \mathrm{kg} /$ min (4 study groups, $n=110$ ), respectively (Fig. 4). There was a significant difference between women and men for the usual pace instruction $(P=0.01)$, with men demonstrating a higher oxygen consumption than women (13.1 vs $11.85 \mathrm{~mL} /$ $\mathrm{kg} / \mathrm{min}$ ). The mean energy expenditure in response to a medium pace instruction was $1229.3 \pm 24.93 \mathrm{~kJ} / \mathrm{h}$ (4 study groups, $n=96$ ) and $16.17 \pm 0.25 \mathrm{~kJ} / \mathrm{kg} / \mathrm{h}$ (4 study groups, $n=110$ ).

\section{Discussion}

This is the first systematic review and meta-analysis to aggregate the results of comparable measures of outdoor walking speed and intensity indicators extracted from methodologically and regionally diverse studies representing more than 14,000 research participants and 13 countries. We demonstrate that outdoor walking speed, cadence, intensity, and energy expenditure increase commensurate with more challenging pace instructions. This systematic review provides the first summary of typical outdoor walking speeds enacted for a range of pace instructions. This summary provides evidence-based reference values against which data from other individuals or future studies can be compared.

The "Compendium of Physical Activities" is widely used as a resource to estimate and classify the energy cost of human physical activity [24]. We determined that an instruction to walk at a slow pace was associated with $0.82 \mathrm{~m} / \mathrm{s}$ (95\% CI 0.77-0.86). This aligns with the Compendium's activity code 17151 , listing walking "less than $0.89 \mathrm{~m} / \mathrm{s}$, level, strolling, very slow" as 2.0 METs. Walking speed associated with usual pace instruction was $1.31 \mathrm{~m} / \mathrm{s}(95 \%$ CI 1.27-1.35), aligning with Compendium activity code 
Table 2 Assessment of study quality

\begin{tabular}{|c|c|c|c|c|c|c|}
\hline Study & $\begin{array}{l}\text { Research } \\
\text { question }\end{array}$ & $\begin{array}{l}\text { Study popu- } \\
\text { lation }\end{array}$ & $\begin{array}{l}\text { Participation } \\
\text { rate }\end{array}$ & $\begin{array}{l}\text { Population and } \\
\text { eligibility }\end{array}$ & $\begin{array}{l}\text { Sample size } \\
\text { justification }\end{array}$ & $\begin{array}{l}\text { Outcome } \\
\text { measures }\end{array}$ \\
\hline Abraham et al. [33] & $\checkmark$ & $\mathrm{x}$ & $\mathrm{O}$ & $\checkmark$ & $\mathrm{x}$ & $\checkmark$ \\
\hline Ali et al. [34] & $\checkmark$ & $\mathrm{x}$ & $\mathrm{O}$ & $\checkmark$ & $\mathrm{x}$ & $\mathrm{O}$ \\
\hline Bargegol et al. [35] & $\checkmark$ & $\mathrm{x}$ & $\mathrm{O}$ & $\mathrm{x}$ & $\mathrm{O}$ & $\mathrm{O}$ \\
\hline Bargegol and Gilani [36] & $\mathrm{x}$ & $\mathrm{x}$ & $\mathrm{O}$ & $\mathrm{x}$ & $\mathrm{O}$ & $\mathrm{O}$ \\
\hline Bassey et al. [22] & $\checkmark$ & $\mathrm{x}$ & $\mathrm{O}$ & $\mathrm{O}$ & $\mathrm{x}$ & $\checkmark$ \\
\hline Braham et al. [37] & $\checkmark$ & $\mathrm{x}$ & $\mathrm{O}$ & $\mathrm{O}$ & $\mathrm{x}$ & $\checkmark$ \\
\hline Brooks et al. [38] & $\checkmark$ & $\mathrm{x}$ & $\mathrm{O}$ & $\mathrm{x}$ & $\checkmark$ & $\checkmark$ \\
\hline Caramia et al. [39] & $\checkmark$ & $\mathrm{x}$ & $\mathrm{O}$ & $\checkmark$ & $\mathrm{x}$ & $\checkmark$ \\
\hline Gates et al. [40] & $\checkmark$ & $\mathrm{x}$ & $\mathrm{O}$ & $\mathrm{x}$ & $\mathrm{x}$ & $\mathrm{x}$ \\
\hline Gunn et al. [17] & $\checkmark$ & $\mathrm{x}$ & $\mathrm{O}$ & $\mathrm{x}$ & $\mathrm{x}$ & $\checkmark$ \\
\hline Gunn et al. [41] & $\checkmark$ & $\mathrm{x}$ & $\mathrm{O}$ & $\mathrm{O}$ & $\checkmark$ & $\checkmark$ \\
\hline Gunn et al. [42] & $\checkmark$ & $\mathrm{x}$ & $\mathrm{O}$ & $\mathrm{O}$ & $\checkmark$ & $\checkmark$ \\
\hline Hills et al. [20] & $\checkmark$ & $\checkmark$ & $\mathrm{O}$ & $\mathrm{O}$ & $\mathrm{x}$ & $\checkmark$ \\
\hline Le Faucher et al. [43] & $\checkmark$ & $\mathrm{x}$ & $\mathrm{O}$ & $\mathrm{x}$ & $\mathrm{x}$ & $\checkmark$ \\
\hline Leicht and Crowther [44] & $\checkmark$ & $\mathrm{x}$ & $\mathrm{O}$ & $\mathrm{x}$ & $\mathrm{x}$ & $\checkmark$ \\
\hline Murtagh et al. [45] & $\checkmark$ & $\mathrm{x}$ & $\mathrm{O}$ & $\mathrm{x}$ & $\mathrm{x}$ & $\checkmark$ \\
\hline Musselwhite [46] & $\checkmark$ & $\mathrm{x}$ & $\mathrm{O}$ & $\mathrm{x}$ & $\mathrm{x}$ & $\checkmark$ \\
\hline Noury-Desvaux et al. [47] & $\checkmark$ & $\mathrm{x}$ & $\mathrm{O}$ & $\mathrm{x}$ & $\mathrm{x}$ & $\checkmark$ \\
\hline Parise et al. [48] & $\checkmark$ & $\checkmark$ & $\mathrm{x}$ & $\checkmark$ & $\mathrm{x}$ & $\checkmark$ \\
\hline Paysant et al. [49] & $\checkmark$ & $\mathrm{x}$ & $\mathrm{O}$ & $\mathrm{O}$ & $\mathrm{x}$ & $\checkmark$ \\
\hline Porcari et al. [18] & $\checkmark$ & $\mathrm{x}$ & $\mathrm{O}$ & $\mathrm{x}$ & $\mathrm{x}$ & $\checkmark$ \\
\hline Prupetkaew et al. [50] & $\checkmark$ & $\mathrm{x}$ & $\mathrm{O}$ & $\checkmark$ & $\mathrm{x}$ & $\checkmark$ \\
\hline Rassafi and Mohajeri [51] & $\checkmark$ & $\mathrm{x}$ & o & $\mathrm{O}$ & $\checkmark$ & $\checkmark$ \\
\hline Sakazaki et al. [52] & $\checkmark$ & $\checkmark$ & $\mathrm{O}$ & $\mathrm{x}$ & $\mathrm{x}$ & $\checkmark$ \\
\hline Sato et al. [53] & $\checkmark$ & $\mathrm{x}$ & $\mathrm{O}$ & $\mathrm{O}$ & $\mathrm{x}$ & $\checkmark$ \\
\hline Scaglioni-Solano and Aragón-Vargas [16] & $\checkmark$ & $\mathrm{x}$ & $\mathrm{O}$ & $\mathrm{O}$ & $\mathrm{x}$ & $\checkmark$ \\
\hline Scaglioni-Solano and Aragón-Vargas [54] & $\checkmark$ & $\mathrm{x}$ & $\mathrm{O}$ & $\mathrm{x}$ & $\mathrm{x}$ & $\checkmark$ \\
\hline Silva et al. [55] & $\checkmark$ & $\mathrm{x}$ & $\mathrm{O}$ & $\mathrm{x}$ & $\mathrm{x}$ & $\checkmark$ \\
\hline Spelman et al. [56] & $\checkmark$ & $\mathrm{x}$ & $\mathrm{O}$ & $\mathrm{x}$ & $\mathrm{x}$ & $\checkmark$ \\
\hline Taylor et al. [57] & $\checkmark$ & $\mathrm{x}$ & $\mathrm{O}$ & $\mathrm{x}$ & $\mathrm{x}$ & $\checkmark$ \\
\hline Washburn and Laporte [58] & $\checkmark$ & $\mathrm{x}$ & $\mathrm{O}$ & $\mathrm{x}$ & $\mathrm{x}$ & $\checkmark$ \\
\hline Waters et al. [59] & $\checkmark$ & $\mathrm{x}$ & $\mathrm{O}$ & $\mathrm{x}$ & $\mathrm{x}$ & $\checkmark$ \\
\hline Waters et al. [60] & $\checkmark$ & $\mathrm{x}$ & $\mathrm{O}$ & $\mathrm{x}$ & $\mathrm{x}$ & $\checkmark$ \\
\hline Wettstein et al. [61] & $\checkmark$ & $\mathrm{x}$ & $\mathrm{O}$ & $\mathrm{x}$ & $\mathrm{x}$ & $\checkmark$ \\
\hline Withers et al. [19] & $\checkmark$ & $\mathrm{x}$ & $\mathrm{O}$ & $\mathrm{x}$ & $\mathrm{x}$ & $\checkmark$ \\
\hline
\end{tabular}

$\checkmark$ yes, $\mathrm{x}$ no, $\mathrm{O}$ other (cannot determine, not applicable, not reported)

17190 ("walking, 1.25-1.43 m/s, level, moderate pace, firm surface") and 3.5 METs. Walking speed associated with a medium pace instruction $(1.47 \mathrm{~m} / \mathrm{s}, 95 \%$ CI $1.44-1.49)$ was slightly faster than this Compendium code's definition. The upper $95 \%$ confidence interval of the walking speed associated with a fast pace instruction $(1.72 \mathrm{~m} / \mathrm{s}, 95 \% \mathrm{CI}$ 1.64-1.81) reached the Compendium's threshold for 5.0 METs. Using the commonly used definition of moderate intensity as 3.0-5.9 METs [25], we estimate that, with the exception of the slow pace instruction, all other pace (i.e. usual, medium, fast, and maximal) instructions provided in the assembled studies would have elicited a walking intensity within a range associated with absolutely defined moderate intensity. This is important as public health guidelines recommend that adults should accumulate at least moderate-intensity aerobic activity [26] to accrue optimal health benefit.

Of note is that the mean walking speed for the maximal pace instruction/description category was lower than the fast category $(1.62 \pm 0.09 \mathrm{~m} / \mathrm{s}$ vs $1.72 \pm 0.05)$. This unusual finding could be because the maximal walking speed test is commonly conducted in older adults-who demonstrate lower 
Table 3 Meta-analyses of walking speed $(\mathrm{m} / \mathrm{s})$ according to pace instruction/description

\begin{tabular}{|c|c|c|c|c|c|c|c|c|}
\hline Pace instruction & Sex & Study groups & $n$ & Mean \pm SE & Lower $95 \%$ CI & Upper 95\% CI & $I^{2}$ & $P$ for sex \\
\hline \multicolumn{9}{|l|}{ Slow } \\
\hline & Females & 2 & 81 & $0.71 \pm 0.09$ & 0.53 & 0.90 & - & - \\
\hline & Males & 2 & 65 & $0.81 \pm 0.03$ & 0.76 & 0.87 & - & 0.31 \\
\hline & Mixed & 5 & 55 & $0.90 \pm 0.07$ & 0.75 & 1.04 & - & - \\
\hline & All & 9 & 201 & $0.82 \pm 0.02$ & 0.77 & 0.86 & 83.95 & - \\
\hline \multicolumn{9}{|l|}{ Usual } \\
\hline & Females & 39 & 6954 & $1.26 \pm 0.04$ & 1.18 & 1.34 & - & - \\
\hline & Males & 37 & 4029 & $1.37 \pm 0.03$ & 1.30 & 1.43 & - & 0.03 \\
\hline & Mixed & 35 & 2626 & $1.28 \pm 0.03$ & 1.21 & 1.35 & - & - \\
\hline & All & 111 & 13,609 & $1.31 \pm 0.02$ & 1.27 & 1.35 & 99.30 & - \\
\hline \multicolumn{9}{|l|}{ Medium } \\
\hline & Females & 2 & 86 & $1.50 \pm 0.03$ & 1.44 & 1.55 & - & - \\
\hline & Males & 3 & 122 & $1.46 \pm 0.02$ & 1.43 & 1.49 & - & 0.18 \\
\hline & Mixed & - & - & - & - & - & - & - \\
\hline & All & 5 & 208 & $1.47 \pm 0.01$ & 1.44 & 1.49 & 47.69 & - \\
\hline \multicolumn{9}{|l|}{ Fast } \\
\hline & Females & 8 & 466 & $1.69 \pm 0.06$ & 1.57 & 1.80 & - & - \\
\hline & Males & 8 & 357 & $1.85 \pm 0.08$ & 1.69 & 2.00 & - & 0.10 \\
\hline & Mixed & 3 & 93 & $1.54 \pm 0.14$ & 1.27 & 1.82 & - & - \\
\hline & All & 19 & 916 & $1.72 \pm 0.05$ & 1.64 & 1.81 & 98.38 & - \\
\hline \multicolumn{9}{|l|}{ Maximal } \\
\hline & Females & 5 & 2122 & $1.57 \pm 0.09$ & 1.38 & 1.75 & - & - \\
\hline & Males & - & - & - & - & - & - & - \\
\hline & Mixed & 2 & 50 & $1.86 \pm 0.20$ & 1.47 & 2.25 & - & - \\
\hline & All & 7 & 2172 & $1.62 \pm 0.09$ & 1.45 & 1.79 & 98.95 & - \\
\hline
\end{tabular}

Significant differences between female and male-only study groups are indicated (bold values) in the $P$ for sex column

$\mathrm{m} / \mathrm{s}$ metres per second, $n$ number of participants, $S E$ standard error, $C I$ confidence interval, $I^{2} I^{2}$ statistic, Females study groups with only female participants, Males study groups with only male participants, Mixed study groups with both female and male participants, All overall value combining all study groups (i.e., female + male + mixed)

maximal walking speed than younger adults-however, as sub-group analysis by age was not possible, this explanation is speculative. The overwhelming majority of participants in studies contributing data to the maximal category were female. Sex differences in walking speed have previously been demonstrated, with men attaining higher speeds in short-distance walking tests than women due to differences in height and leg length [27, 28].

Studies that include measures of absolute intensity (e.g., METs) and/or relative intensity (e.g., percentage maximal heart rate) can offer a more direct indication of whether or not a specific walking speed can reach public health moderate-intensity guidelines. There is a strong relationship between cadence and intensity, with $>100$ steps/min established as a threshold value associated with absolutely defined moderate intensity [29]. For both the usual pace and fast pace categories, steps/min exceeded this threshold, with the fast pace averaging 126.8 steps/ min (95\% CI 121.9-131.6). Similarly, the mean METs observed for the medium pace instruction of 4.2 METs (95\% CI 3.9-4.5) are concordant with the commonly used definition of moderate intensity of 3.0-5.9 METs [25]. However, in terms of common definitions of relative exercise intensity, the medium pace instruction only elicited a heart rate response $55.9 \% \mathrm{HR}_{\max }$ (95\% CI 54.1-57.6) that would be considered only very light intensity [25]. Moderate intensity is considered to be $64-79 \% \mathrm{HR}_{\max }$ [25]. Our finding that medium pace instruction only evoked light intensity may be due to the age and fitness of participants. Maximum heart rate declines with age. We note that both of the three studies from which these groups-providing data on percentage maximal heart rate in response to the medium pace instruction-are drawn reported a mean age of 40 years. These younger individuals with a higher maximal heart rate will need to walk at a faster pace to reach $64 \%$ of their $\mathrm{HR}_{\max }$ compared to older individuals with a lower maximum. Furthermore, within any age group, individuals with higher levels of 
Fig. 2 Mean walking speed $(\mathrm{m} / \mathrm{s})$. The dashed lines represent the trend for mean speed by pace instruction, separated by sub-group units based on sex (female [triangle], male [square with cross], and mixed sex [open square]). The solid line represents the overall trend for mean speed including all subgroups. Breaks in the lines represent missing data points for that particular sub-group and pace instruction (i.e., mixed medium and maximal males)

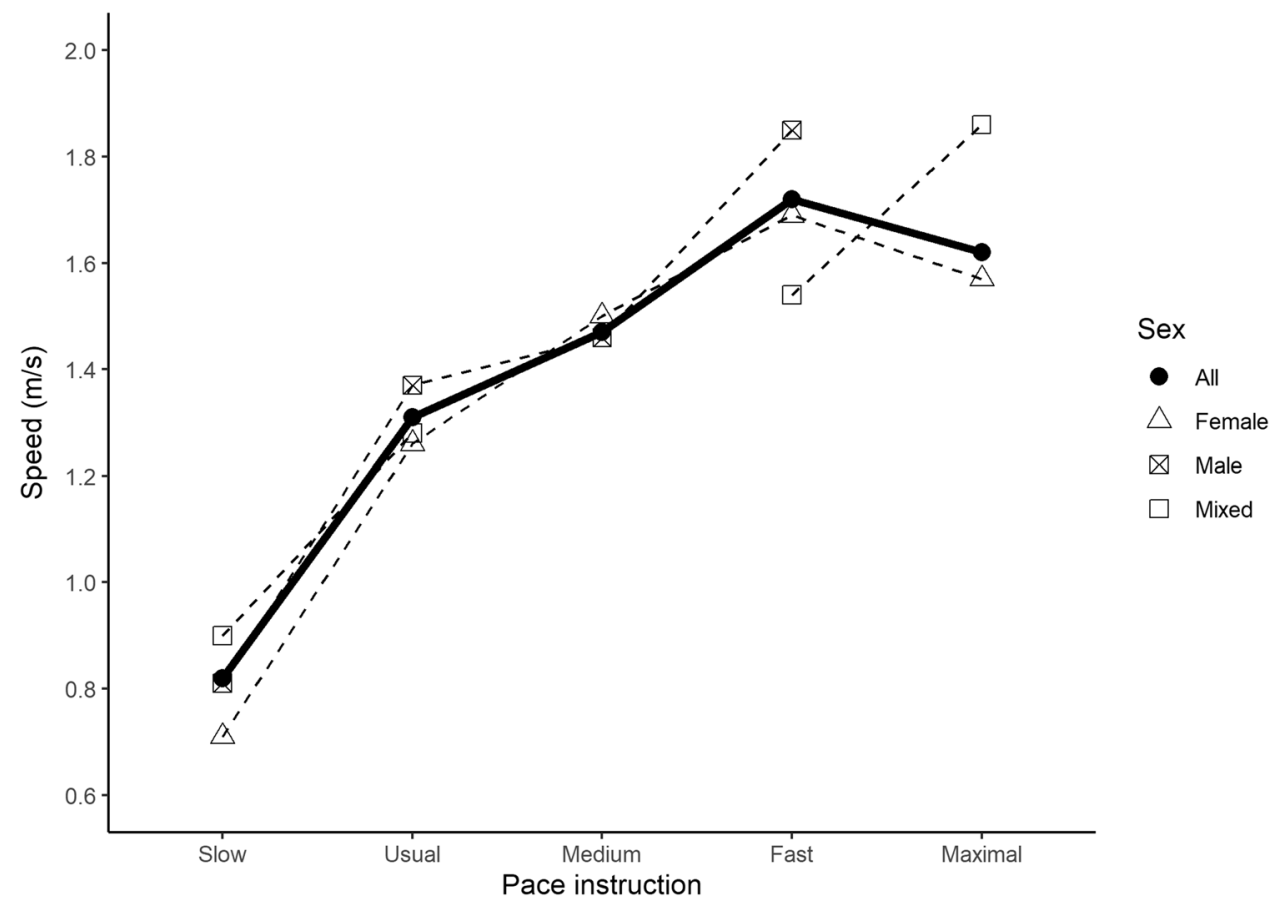

Table 4 Meta-analyses of walking cadence (steps/min) according to pace instruction/description

\begin{tabular}{|c|c|c|c|c|c|c|c|c|}
\hline Pace instruction & Sex & Study groups & $n$ & Mean \pm SE & Lower $95 \%$ CI & Upper $95 \%$ CI & $I^{2}$ & $P$ for sex \\
\hline \multicolumn{9}{|l|}{ Usual } \\
\hline & Females & 17 & 533 & $121.88 \pm 1.48$ & 118.99 & 124.77 & - & - \\
\hline & Males & 20 & 285 & $113.69 \pm 1.34$ & 111.07 & 116.32 & - & $<0.01$ \\
\hline & Mixed & 8 & 121 & $114.22 \pm 1.79$ & 110.70 & 117.74 & - & - \\
\hline & All & 45 & 939 & $116.65 \pm 0.87$ & 114.95 & 118.35 & 96.04 & - \\
\hline \multicolumn{9}{|l|}{ Fast } \\
\hline & Females & 3 & 171 & $133.04 \pm 4.61$ & 124.00 & 142.08 & - & - \\
\hline & Males & 3 & 97 & $124.16 \pm 2.96$ & 118.35 & 129.96 & - & 0.10 \\
\hline & Mixed & - & - & - & - & - & - & - \\
\hline & All & 6 & 268 & $126.75 \pm 2.49$ & 121.87 & 131.63 & 99.49 & - \\
\hline
\end{tabular}

steps/min steps per minute, $n$ number of participants, $S E$ standard error, $C I$ confidence interval, $I^{2} I^{2}$ statistic, Females study groups with only female participants, Males study groups with only male participants, Mixed study groups with both female and male participants, All overall value combining all study groups (i.e., female + male + mixed)

Significant differences between female and male-only study groups are indicated (bold values) in the $P$ for sex column

cardiorespiratory fitness (and therefore larger cardiac output) will have less elevation in HR at a given speed than those with lower levels of fitness.

We note that a greater relative exercise intensity was observed for females $\left(61.0 \% \mathrm{HR}_{\max }\right)$ compared to males $\left(53.1 \% \mathrm{HR}_{\max }\right)$ in response to the medium pace instruction. This gender difference may be explained by the known lower cardiac output (due to smaller heart size) and lean body mass of females compared to males at a given age [30]

\subsection{Limitations}

Several limitations of this systematic review and metaanalysis are noted. First, our assessment of study quality noted that while the research question and outcomes measures were clearly stated in nearly all studies, many failed to clearly specify the study population. For example, often only subject numbers and location were reported. There is the possibility of selection bias in some studies. Also, in most cases, a sample size justification, power description, or variance and effect estimates were not reported in the original study. These threats to internal validity may increase 
Fig. 3 Mean walking cadence $(\mathrm{m} / \mathrm{s})$. The dashed lines represent the trend for mean cadence by pace instruction, separated by sub-group units based on sex (female [triangle] and male [square with cross]). The solid line represents the overall trend for mean cadence including all subgroups

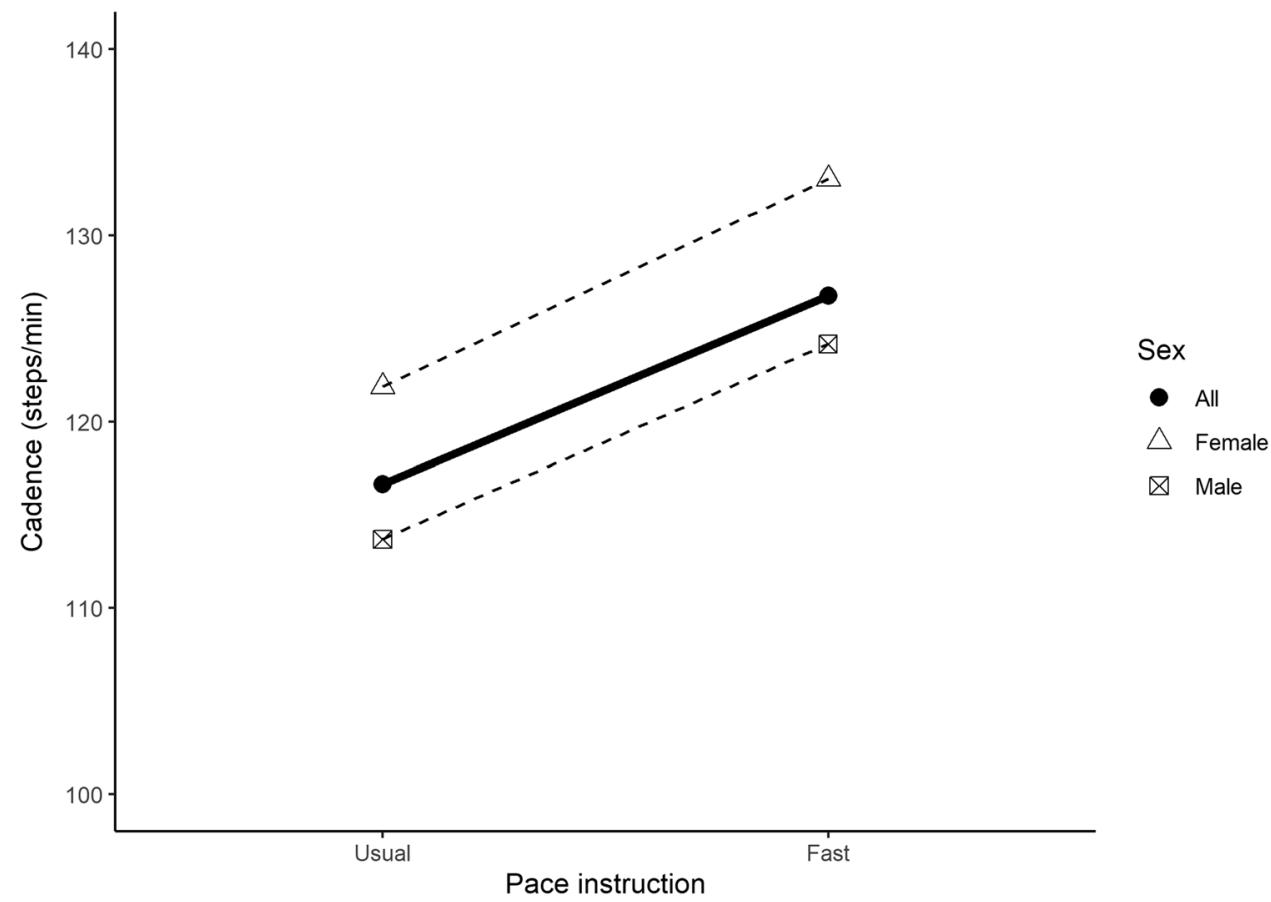

Table 5 Meta-analyses of intensity outcomes according to pace instruction/description

\begin{tabular}{|c|c|c|c|c|c|c|c|c|}
\hline $\begin{array}{l}\text { Outcome and pace } \\
\text { instruction }\end{array}$ & Sex & Study groups & $n$ & Mean \pm SE & Lower $95 \%$ CI & Upper $95 \%$ CI & $I^{2}$ & $P$ for sex \\
\hline \multicolumn{9}{|l|}{ METs } \\
\hline \multicolumn{9}{|l|}{ Medium } \\
\hline & Females & 3 & 98 & $4.14 \pm 0.18$ & 3.79 & 4.48 & - & - \\
\hline & Males & 4 & 134 & $4.36 \pm 0.26$ & 3.85 & 4.86 & - & 0.48 \\
\hline & Mixed & - & - & - & - & - & - & - \\
\hline & All & 7 & 232 & $4.21 \pm 0.14$ & 3.92 & 4.49 & 91.70 & - \\
\hline \multicolumn{9}{|l|}{$\% \mathrm{HR}_{\max }$} \\
\hline \multicolumn{9}{|l|}{ Medium } \\
\hline & Females & 1 & 36 & $61.00 \pm 1.50$ & 58.06 & 63.94 & - & - \\
\hline & Males & 3 & 122 & $53.09 \pm 1.10$ & 50.93 & 55.25 & - & $<0.01$ \\
\hline & Mixed & - & - & - & - & - & - & - \\
\hline & All & 4 & 158 & $55.86 \pm 0.89$ & 54.12 & 57.60 & 89.55 & - \\
\hline
\end{tabular}

Significant differences between female and male-only study groups are indicated (bold values) in the $P$ for sex column

$n$ number of participants, $S E$ standard error, $C I$ confidence interval, $I^{2} I^{2}$ statistic, $M E T s$ metabolic equivalents, $\% H R_{\max }$ percentage maximal heart rate, Females study groups with only female participants, Males study groups with only male participants, Mixed study groups with both female and male participants, All overall value combining all study groups (i.e., female + male + mixed)

the risk for bias. Second, the purpose of walking was not considered (e.g., for commuting and for recreation) but may theoretically have an effect on enacted walking speed. Third, a variety of tests/protocols were used to measure walking pace, and therefore across studies, there is no standardised assessment method. Fourth, there were not sufficient data available on age to permit sub-group analysis. Fifth, as we restricted our search to articles published in English, it is possible that there are additional studies published in other languages that could augment this evidence base. Finally, studies undertaken in Australia and the US contributed 23\% and $20 \%$ of all included studies; therefore, findings may not be representative of broader populations. Our assessment of study quality indicates the need for better designed and executed studies, although it is possible that they only neglected to report on assessed items. We note that several guidelines are gaining prominence which aims to enhance standardised reporting of observational studies (e.g., the STROBE statement [31]). Adherence to such guidelines should enhance the secondary use and analysis of data. 
Table 6 Meta-analyses of oxygen consumption and energy expenditure outcomes according to pace instruction/description

\begin{tabular}{|c|c|c|c|c|c|c|c|c|}
\hline $\begin{array}{l}\text { Outcome and pace } \\
\text { instruction }\end{array}$ & Sex & Study groups & $n$ & Mean $\pm \mathrm{SE}$ & Lower $95 \%$ CI & Upper $95 \%$ CI & $I^{2}$ & $P$ for sex \\
\hline \multicolumn{9}{|l|}{$\mathrm{mL} / \mathrm{kg} / \mathrm{min}$} \\
\hline \multicolumn{9}{|l|}{ Usual } \\
\hline & Females & 4 & 151 & $11.85 \pm 0.15$ & 11.56 & 12.15 & - & - \\
\hline & Males & 7 & 136 & $13.10 \pm 0.47$ & 12.18 & 14.03 & - & 0.01 \\
\hline & Mixed & - & - & - & - & - & - & - \\
\hline & All & 11 & 287 & $11.97 \pm 0.14$ & 11.69 & 12.25 & 99.31 & - \\
\hline \multicolumn{9}{|l|}{ Medium } \\
\hline & Females & 1 & 12 & $13.50 \pm 0.98$ & 11.58 & 15.42 & - & - \\
\hline & Males & 3 & 98 & $13.33 \pm 0.20$ & 12.93 & 13.73 & - & 0.86 \\
\hline & Mixed & - & - & - & - & - & - & - \\
\hline & All & 4 & 110 & $13.34 \pm 0.20$ & 12.94 & 13.73 & 0.00 & - \\
\hline \multicolumn{9}{|l|}{$\mathrm{kJ} / \mathrm{h}$} \\
\hline \multicolumn{9}{|l|}{ Medium } \\
\hline & Females & 2 & 48 & $1153.33 \pm 32.83$ & 1088.97 & 1217.68 & - & - \\
\hline & Males & 2 & 48 & $1332.68 \pm 38.30$ & 1257.61 & 1407.74 & - & $<0.01$ \\
\hline & Mixed & - & - & - & - & - & - & - \\
\hline & All & 4 & 96 & $1229.30 \pm 24.93$ & 1180.44 & 1278.16 & 77.91 & - \\
\hline \multicolumn{9}{|l|}{$\mathrm{kJ} / \mathrm{kg} / \mathrm{h}$} \\
\hline \multicolumn{9}{|l|}{ Medium } \\
\hline & Females & 1 & 12 & $16.50 \pm 1.27$ & 14.01 & 18.99 & - & - \\
\hline & Males & 3 & 98 & $16.16 \pm 0.25$ & 15.67 & 16.65 & - & 0.79 \\
\hline & Mixed & - & - & - & - & - & - & - \\
\hline & All & 4 & 110 & $16.17 \pm 0.25$ & 15.69 & 16.66 & 0.00 & - \\
\hline
\end{tabular}

Significant differences between female and male-only study groups are indicated (bold values) in the $P$ for sex column

Females study groups with only female participants, Males study groups with only male participants, Mixed study groups with both female and male participants, $A l l$ overall value combining all study groups (i.e., female + male + mixed)

Fig. 4 Mean walking oxygen uptake $(\mathrm{mL} / \mathrm{kg} / \mathrm{min})$. The dashed lines represent the trend for mean oxygen uptake by pace instruction, separated by sub-group units based on sex (female [triangle], male [square with cross]). The solid line represents the overall trend for mean oxygen uptake including all subgroups

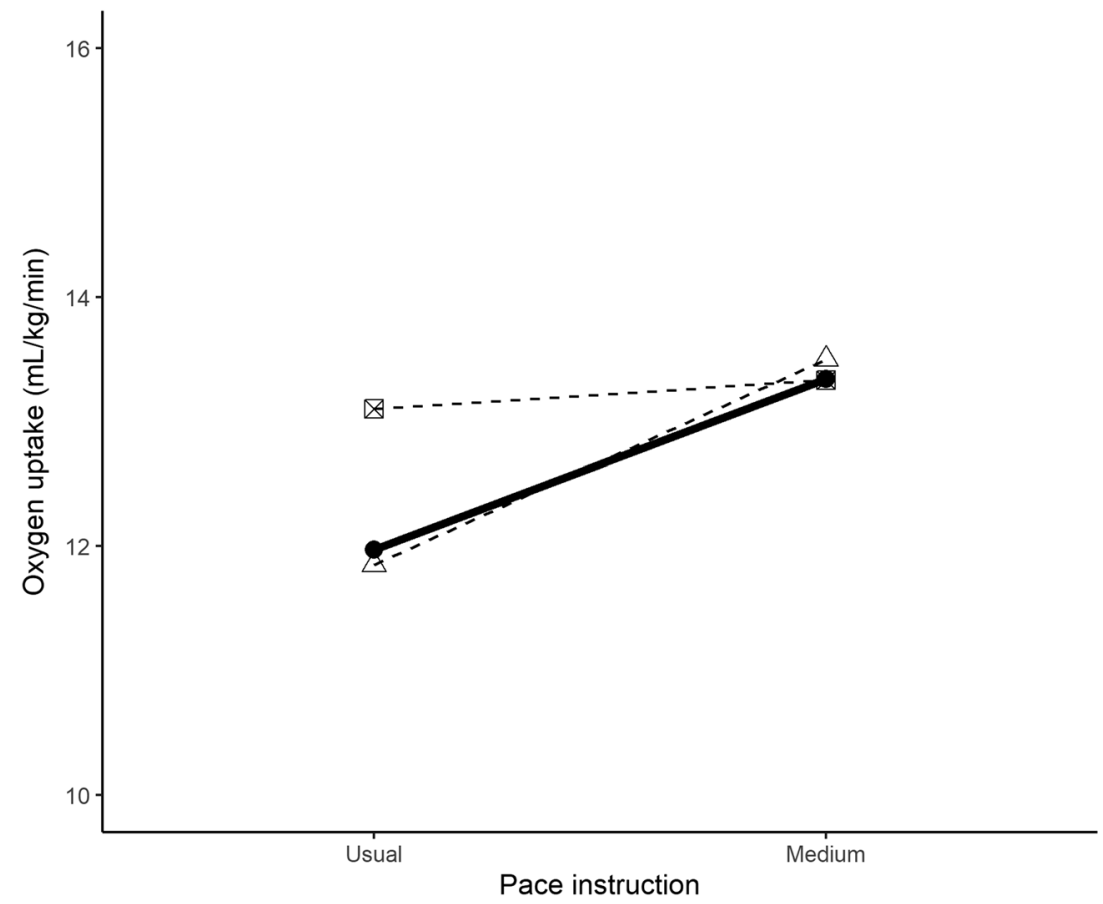




\subsection{Implications for Research}

Our analyses highlight participant subgroups where data were not available. For example, no cadence data were available for slow or medium paces. Furthermore, we could only present relative intensity findings in terms of $\% \mathrm{HR}_{\max }$ and only specifically for medium pace instruction. In addition, due to a lack of data, we were unable to provide any age-specific expected values. These gaps in the evidence base should be addressed in future studies.

Findings on outdoor walking pace would be enhanced with standardised data collection that includes participants' height, BMI, and leg length, as these are known to influence gait speed [32]. However, we acknowledge that for studies that observe "real world" walking speed in outdoor settings, it is difficult to always capture these data. A trade-off must be made between observation of large numbers of individuals (thus enhancing the precision of results) and collecting anthropometric data on each individual (thereby enhancing the applicability of findings to specific subgroups).

\section{Conclusion}

As noted above, walking speed is related to intensity. In a controlled setting, it is easier to set a speed (e.g., on a treadmill) to elicit a desired intensity level. Without relying on more advanced wearable technologies, it is more challenging to elicit a specific intensity, let alone a specific speed, without clear instruction. The amalgamated data herein provide expected values (where available) for speed, cadence, percent maximal heart rage, and oxygen consumption for slow through maximal paced walking. Walking at a self-selected (usual) pace was associated with an average speed of $1.31 \mathrm{~m} / \mathrm{s}$, a cadence of $116.65 \mathrm{steps} /$ $\mathrm{min}$, and an oxygen consumption of $11.97 \mathrm{~mL} / \mathrm{kg} / \mathrm{min}$, meeting/exceeding public health thresholds for moderateintensity activity The assembled information provides greater clarity with regard to how various indicators of enacted walking pace, speed, and intensity overlap and how each can be best communicated in the real-world setting to optimise health-related outcomes. Pace-based instructions can be used to support walking in outdoor settings within public health guidelines.

\section{Declarations}

Funding No funding was received for the conduct of this review and/ or preparation of this manuscript.
Conflict of interest Elaine Murtagh, Jacqueline Mair, Elroy Aguair, Catrine Tudor-Locke, and Marie Murphy declare that they have no conflicts of interest relevant to the content of this review.

Ethics approval Not applicable.

Consent to participate Not applicable.

Consent for publication Not applicable.

Data Availability Statement The dataset generated during the current review is available in the OSF repository, https://osf.io/uypx6/?view_ only $=\mathrm{e} 7 \mathrm{~b} 6071 \mathrm{fc} 2 \mathrm{ec} 4 \mathrm{e} 04 \mathrm{~b} 1140620 \mathrm{fc} 716 \mathrm{e} 51$.

Code availability Not applicable.

Author contributions EM and MM devised the idea for the article. JM carried out the search. EA carried out the data analysis. All authors drafted and critically revised the work.

Open Access This article is licensed under a Creative Commons Attribution 4.0 International License, which permits use, sharing, adaptation, distribution and reproduction in any medium or format, as long as you give appropriate credit to the original author(s) and the source, provide a link to the Creative Commons licence, and indicate if changes were made. The images or other third party material in this article are included in the article's Creative Commons licence, unless indicated otherwise in a credit line to the material. If material is not included in the article's Creative Commons licence and your intended use is not permitted by statutory regulation or exceeds the permitted use, you will need to obtain permission directly from the copyright holder. To view a copy of this licence, visit http://creativecommons.org/licenses/by/4.0/.

\section{References}

1. Hulteen RM, Smith JJ, Morgan PJ, Barnett LM, Hallal PC, Colyvas $\mathrm{K}$, et al. Global participation in sport and leisure-time physical activities: a systematic review and meta-analysis. Prev Med. 2017;95:14-25.

2. Morris JN, Hardman AE. Walking to health. Sports Med. 1997;23(5):306-32.

3. Lee IM, Skerrett PJ. Physical activity and all-cause mortality: what is the dose- response relation? Med Sci Sports Exerc. 2001;33(6):S459-S471471.

4. Department of Health. UK chief medical officers' physical activity guidelines. London: Department of Health; 2019.

5. Shephard RJ. Absolute versus relative intensity of physical activity in a dose-response context. Med Sci Sports Exerc. 2001;33(6):400-18.

6. Hamer M, Chida Y. Walking and primary prevention: a metaanalysis of prospective cohort studies. Br J Sports Med. 2008;42(4):238-43.

7. Saevereid HA, Schnohr P, Prescott E. Speed and duration of walking and other leisure time physical activity and the risk of heart failure: a prospective cohort study from the Copenhagen city heart study. PLoS ONE. 2014;9(3):e89909.

8. Bohannon RW, Andrews AW. Normal walking speed: a descriptive meta-analysis. Physiotherapy. 2011;97(3):182-9.

9. Graham JE, Fisher SR, Bergés I-M, Kuo Y-F, Ostir GV. Walking speed threshold for classifying walking independence in hospitalized older adults. Phys Ther. 2010;90(11):1591-7. 
10. Peel NM, Kuys SS, Klein K. Gait speed as a measure in geriatric assessment in clinical settings: a systematic review. J Gerontol Ser A Biol Sci Med Sci. 2013;68(1):39-46.

11. Woo J. Walking speed: a summary indicator of frailty? J Am Med Dir Assoc. 2015;16(8):635-7.

12. Schimpl M, Lederer C, Daumer M. Development and validation of a new method to measure walking speed in free-living environments using the actibelt ${ }^{\circledR}$ platform. PLoS ONE. 2011;6(8):e23080.

13. Murtagh E, Mair J, Aguair E, Tudor-Locke C, Murphy M. Selfselected walking speed of apparently healthy adults: a systematic review and meta-analysis. Prospero 2017 crd42017051911. 2017. https://www.crd.york.ac.uk/prospero/display_recor d.php?ID=CRD42017051911.

14. Veritas Health Innovation. Covidence systematic review software, Melbourne, Australia.

15. Sargeant J, O'Connor A. Conducting systematic reviews of intervention questions ii: relevance screening, data extraction, assessing risk of bias, presenting the results and interpreting the findings. Zoonoses Public Health. 2014;61:39-51.

16. Scaglioni-Solano P, Aragón-Vargas LF. Age-related differences when walking downhill on different sloped terrains. Gait Posture. 2015;41(1):153-8.

17. Gunn SM, Brooks AG, Withers RT, Gore CJ, Owen N, Booth ML, et al. Determining energy expenditure during some household and garden tasks. Med Sci Sports Exerc. 2002;34(5):895-902.

18. Porcari J, McCarron R, Kline G, Freedson PS, Ward A, Ross JA, et al. Is fast walking an adequate aerobic training stimulus for 30- to 69-year-old men and women? Phys Sportsmed. 1987;15(2):119-29.

19. Withers RT, Brooks AG, Gunn SM, Plummer JL, Gore CJ, Cormack J. Self-selected exercise intensity during household/ garden activities and walking in 55 to 65 -year-old females. Eur J Appl Physiol. 2006;97(4):494-504.

20. Hills AP, Byrne NM, Wearing S, Armstrong T. Validation of the intensity of walking for pleasure in obese adults. Prev Med. 2006;42(1):47-50.

21. National Institutes of Health. Quality assessment tool for observational cohort and cross-sectional studies. 2014 [cited 2018 12th September]. https://www.nhlbi.nih.gov/health-pro/guide lines/in-develop/cardiovascular-risk-reduction/tools/cohort.

22. Bassey E, Bendall M, Pearson M. Muscle strength in the triceps surae and objectively measured customary walking activity in men and women over 65 years of age. Clin Sci. 1988;74(1):85-9.

23. Bendall M, Bassey E, Pearson M. Factors affecting walking speed of elderly people. Age Ageing. 1989;18(5):327-32.

24. Ainsworth BE, Haskell WL, Herrmann SD, Meckes N, Bassett DR Jr, Tudor-Locke C, et al. 2011 compendium of physical activities: a second update of codes and met values. Med Sci Sports Exerc. 2011;43(8):1575-81.

25. Ewing Garber C, Blissmer B, Deschenes MR, Franklin B, Lamonte MJ, Lee I-M, et al. American college of sports medicine position stand. Quantity and quality of exercise for developing and maintaining cardiorespiratory, musculoskeletal, and neuromotor fitness in apparently healthy adults: guidance for prescribing exercise. Med Sci Sports Exerc. 2011;43(7):1334-599.

26. World Health Organization. Global recommendations on physical activity for health. Geneva: WHO; 2010.

27. Tolea MI, Costa PT, Terracciano A, Griswold M, Simonsick EM, Najjar SS, et al. Sex-specific correlates of walking speed in a wide age-ranged population. J Gerontol B Psychol Sci Soc Sci. 2010;65(2):174-84

28. Frimenko R, Whitehead C, Bruening D. Do men and women walk differently? A review and meta-analysis of sex difference in nonpathological gait kinematics. Dayton: Infoscitex Corp; 2014.
29. Tudor-Locke C, Han H, Aguiar EJ, Barreira TV, Schuna JM Jr, Kang M, et al. How fast is fast enough? Walking cadence (steps/ $\mathrm{min})$ as a practical estimate of intensity in adults: a narrative review. Br J Sports Med. 2018;52(12):776-88.

30. Prabhavathi K, Selvi KT, Poornima K, Sarvanan A. Role of biological sex in normal cardiac function and in its disease outcome-a review. J Clin Diagn Res. 2014;8(8):BE01.

31. Von Elm E, Altman DG, Egger M, Pocock SJ, Gøtzsche PC, Vandenbroucke JP, et al. The strengthening the reporting of observational studies in epidemiology (strobe) statement: guidelines for reporting observational studies. J Clin Epidemiol. 2008;61(4):344-9.

32. Zatsiorky VM, Werner SL, Kaimin MA. Basic kinematics of walking. Step length and step frequency. A review. J Sports Med Phys Fit. 1994;34(2):109-34.

33. Abraham P, Noury-Desvaux B, Gernigon M, Mahé G, Sauvaget T, Leftheriotis $\mathrm{G}$, et al. The inter-and intra-unit variability of a lowcost gps data logger/receiver to study human outdoor walking in view of health and clinical studies. PLoS ONE. 2012;7(2):e31338.

34. Ali AA, Yamin F, Kumar S, Khan N, Paracha H, Batool S. Screening of bmi in biomechenical parameters of gait in young adults. Indian J Physiother Occup Ther. 2017;11(3): 104.

35. Bargegol I, Taghizadeh N, Gilani VNM. Evaluation of pedestrians speed with investigation of un-marked crossing. Comput Sci. 2015;12:150-5.

36. Bargegol I, Gilani VNM. The effect of rainy weather on walking speed of pedestrians on sidewalks. Buletin Teknol Tanaman. 2015;12:217-22.

37. Braham R, Rosenberg M, Begley B. Can we teach moderate intensity activity? Adult perception of moderate intensity walking. J Sci Med Sport. 2012;15(4):322-6.

38. Brooks AG, Gunn SM, Withers RT, Gore CJ, Plummer JL. Predicting walking mets and energy expenditure from speed or accelerometry. Med Sci Sports Exerc. 2005;37(7):1216-23.

39. Caramia C, Bernabucci I, D'Anna C, De Marchis C, Schmid M. Gait parameters are differently affected by concurrent smartphonebased activities with scaled levels of cognitive effort. PLoS ONE. 2017;12(10):e0185825.

40. Gates TJ, Noyce DA, Bill AR, Van Ee N. Recommended walking speeds for timing of pedestrian clearance intervals based on characteristics of the pedestrian population. Transport Res Rec. 2006;1982(1):38-47.

41. Gunn SM, van der Ploeg GE, Withers RT, Gore CJ, Owen N, Bauman AE, et al. Measurement and prediction of energy expenditure in males during household and garden tasks. Eur J Appl Physiol. 2004;91(1):61-70.

42. Gunn SM, Brooks AG, Withers RT, Gore CJ, Plummer JL, Cormack J. The energy cost of household and garden activities in 55-to 65-year-old males. Eur J Appl Physiol. 2005;94(4):476-86.

43. Le Faucheur A, Abraham P, Jaquinandi V, Bouye P, Saumet JL, Noury-Desvaux B. Study of human outdoor walking with a lowcost gps and simple spreadsheet analysis. Med Sci Sports Exerc. 2007;39(9):1570-8.

44. Leicht AS, Crowther RG. Pedometer accuracy during walking over different surfaces. Med Sci Sports Exerc. 2007;39(10):1847-50.

45. Murtagh EM, Boreham CAG, Murphy MH. Speed and exercise intensity of recreational walkers. Prev Med. 2002;35(4):397-400.

46. Musselwhite C. Environment-person interactions enabling walking in later life. Transport Plan Technol. 2015;38(1):44-61.

47. Noury-Desvaux B, Abraham P, Mahé G, Sauvaget T, Leftheriotis G, Le Faucheur A. The accuracy of a simple, low-cost gps data logger/receiver to study outdoor human walking in view of health and clinical studies. PLoS ONE. 2011;6(9):e23027.

48. Parise C, Sternfeld B, Samuels S, Tager IB. Brisk walking speed in older adults who walk for exercise. J Am Geriatr Soc. 2004;52(3):411-6. 
49. Paysant J, Beyaert C, Datié A-M, Martinet N, André J-M. Influence of terrain on metabolic and temporal gait characteristics of unilateral transtibial amputees. J Rehabil Res Dev. 2006;43(2):153-60.

50. Prupetkaew P, Lugade V, Kamnardsiri T, Silsupadol P. Cognitive and visual demands, but not gross motor demand, of concurrent smartphone use affect laboratory and free-living gait among young and older adults. Gait Posture. 2019;68:30-6.

51. Rassafi AA, Mohajeri F. Analysis of walking patterns in a pedestrian environment using cellular automata. In: Proceedings of the Institution of Civil Engineers-Municipal Engineer. Thomas Telford Ltd; 2019. p. 37-45.

52. Sakazaki T, Koike T, Yanagimoto Y, Oshida Y. Association between gait speed and bone strength in community-dwelling postmenopausal Japanese women. Environ Health Prev Med. 2012;17(5):394.

53. Sato H, Ishizu K. Gait patterns of Japanese pedestrians. J Hum Ergol. 1990;19(1):13-22.

54. Scaglioni-Solano P, Aragón-Vargas LF. Gait characteristics and sensory abilities of older adults are modulated by gender. Gait Posture. 2015;42(1):54-9.

55. Silva AMCB, da Cunha JRR, da Silva JPC. Estimation of pedestrian walking speeds on footways. Proc Inst Civ Eng. 2014;167(1):32-433.
56. Spelman CC, Pate RR, Macera CA, Ward DS. Self-selected exercise intensity of habitual walkers. Med Sci Sports Exerc. 1993;25(10):1174-9.

57. Taylor KL, Fitzsimons C, Mutrie N. Objective and subjective assessments of normal walking pace, in comparison with that recommended for moderate intensity physical activity. Int J Exerc Sci. 2010;3(3):87-96.

58. Washburn RA, Laporte RE. Assessment of walking behavior: effect of speed and monitor position on two objective physical activity monitors. Res Q Exerc Sport. 1988;59(1):83-5.

59. Waters RL, Lunsford BR, Perry J, Byrd R. Energy-speed relationship of walking: standard tables. J Orthop Res. 1988;6(2):215-22.

60. Waters RL, Hislop HJ, Perry J, Thomas L, Campbell J. Comparative cost of walking in young and old adults. J Orthop Res. 1983;1(1):73-6.

61. Wettstein M, Wahl H-W, Shoval N, Oswald F, Voss E, Seidl $\mathrm{U}$, et al. Out-of-home behavior and cognitive impairment in older adults: findings of the Sentra project. J Appl Gerontol. 2015;34(1):3-25. 